\title{
PERBANDINGAN KINERJA METODE BARISAN FIBONACCI DAN REGULA FALSE DALAM PENENTUAN PERBANDINGAN EMAS
}

\author{
ENDARYONO \\ Program Studi Informatika \\ Universitas Indraprasta PGRI \\ Jalan Raya Tengah Kelurahan Gedong Pasar Rebo Jakarta Timur \\ Email: endaryono@unindra.ac.id
}

\begin{abstract}
Abstrak. Banyak metode dalam menentukan perbandingan emas (golden ratio) dan diantaranya adalah metode barisan Fibonacci dan regula-falsi fungsi persamaan kuadrat. Tulisan ini bertujuan menganalisa kinerja komputasi metode barisan Fobonacci dan metode regula-falsi persamaan kuadrat dalam menentukan nilai perbandingan emas. Penelitian dilakukan dengan eksperimen melalui simulasi program matlab versi 7.1. Hasil simulasi menunjukkan bahwa metode regula-false fungsi persamaan kuadrat memberikan kinerja yang lebih baik dalam jumlah iterasi dan waktu running dibanding dengan metode barisan Fibonacci pada penentuan nilai perbandingan emas.
\end{abstract}

Kata Kunci: Perbandingan emas, Fibonacci, regula-false

\begin{abstract}
Many methods of determining the golden ratio and among them are the Fibonacci sequence method and the regula-falsi functions of quadratic equations. This paper aims to analyze the computational performance of the Fibonacci sequence method and the regula-falsi functions of quadratic equations method in determining the value of the gold ratio. The research was carried out by experiments through the simulation of the Matlab program version 7.1. Simulation results show that the regula-falsi functions of quadratic equations method gives better performance in the number of iterations and running time compared to the Fibonacci sequence method in determining the value of the gold ratio.
\end{abstract}

Key words: golden ratio, Fibonacci, regula-false

\section{PENDAHULUAN}

Nilai perbandingan emas atau golden ratio disimbolkan dengan huruf yunani $\varphi$ (phi) telah lama dikenal. Nilai $\varphi$ berkisar pada 1,618 dan merupakan bilangan irrasional. Penggunaan nilai ini banyak dikenal pada geomateri, seni, arsitektur dan lain-lain. Suatu keindahan dalam seni arsitektur diukur dengan kesesuaian pada nilai perbandingan emas.

Dalam lukisan Monalisa karya seniman Italia, Leonardo da Vinci, terdapat perbandingan tinggi dan lebar lukisan wajah Monalisa adalah 1,618. Bangunan Parthenon di Yunani, perbandingan antar bagian-bagian di daerah tampak depan adalah 1,618.

Perbandingan emas juga terdapat dalam tubuh manusia. Perbandingan antara tinggi dengan jarak antara pusar dan kaki setara 1,618. Jarak antara pergelangan tangan dan siku adalah 1 maka jarak antara ujung jari dan siku akan menjadi 1,618. (Omotehinwa T.O and Ramon S.O, 2013). Dalam tulisan Gabriele Fici (2015), nilai perbandingan emas didapat melalui persamaan rekursif barisan Fibonacci. Jurnal yang ditulis Md. Akhtaruzzaman dan Amir A. Shafie (2011) menuliskan bahwa nilai persamaan emas juga didapat dengan melakukan perbandingan posisi titik pada sebuah segmen garis lurus sedemikian sehingga didapat posisi emas dan persamaan kuadrat. Penelitian oleh Danang Tri Massandy (2012) membandingkan 6 metode numerik dalam penentuan nilai perbandingan emas, yaitu metode bagi dua, regula falsi, lelaran titik tetap, newton raphson, secant dan HouseHolds yang diimplementasikan dalam bahasa fortran 90. Penelitian menyatakan bahwa 
metode HousHolds cocok digunakan untuk mendapatkan nilai perbandingan emas di antara 5 metode lainnya.

Penelitian ini dilakukan untuk memahami bagaimana kinerja komputasi dari metode barisan Fibonacci dan metode persamaan kuadrat perbandingan posisi titik pada segmen garis lurus dalam penentuan nilai perbandingan emas. Untuk hal tersebut dilakukan eksperimen melalui simulasi program matlab versi 7.1. Diharapkan penelitian dapat menambah hasanah keilmuan para mahasiswa, guru dan peminat matematika dalam memahami kinerja komputasi pada suatu metode.

\section{METODE}

Penentuan nilai perbandingan emas dalam tulisan ini menggunakan fungsi rekursif barisan Fibonacci dan fungsi eksplisit persamaan kuadrat dari sebuah segment garis lurus dengan posisi titik bagian emas.

\section{Teori Fibonacci}

Teori Fobonacci adalah satu di antara beberapa metode untuk mendapatkan nilai rasio emas. Barsian Fibonacci ditemukan oleh Leonardo da Pisa atau Leonardo Pisano (1175-1250) matematikawan asal Perancis.

Teori Fibonacci didasari oleh suatu permasalahan sepasang kelinci muda, jantan dan betina, diletakkan di suatu pulau. Setelah berumur dua bulan setiap pasangan kelinci akan melahirkan sepasang kelinci baru dengan frekuensi sekali sebulan. Permasalahan, berapa banyak kelinci di sana setelah $\mathrm{n}$ bulan? Dalam hal ini di asumsikan tidak ada kelinci yang mati. Permasalahan tersebut dijawab dengan suatu barisan Fibonacci

$\mathrm{F}_{1}=1, \mathrm{~F}_{2}=1$,

Untuk setiap $n>2$,

$\mathrm{F}_{\mathrm{n}}=\mathrm{F}_{\mathrm{n}-1}+\mathrm{F}_{\mathrm{n}-2} \quad$ Persamaan (1)

Maka didapat barisan Fibonacci :

$1,1,2,3,5,8,13,21,34,55,89, \ldots$

Sedangkan nilai perbandingan emas atau golden ratio didapatkan dengan cara membandingkan suatu suku dengan suku sesudahnya dalam barisan Fibonacci.

$$
G_{n}=\frac{F_{n+1}}{F_{n}} \quad \text { Persamaan }
$$

Karena:

$\mathrm{F}_{\mathrm{n}}=\mathrm{F}_{\mathrm{n}-1}+\mathrm{F}_{\mathrm{n}-2}$

$\mathrm{F}_{\mathrm{n}+1}=\mathrm{F}_{\mathrm{n}}+\mathrm{F}_{\mathrm{n}-1}$

Sehingga :

$G_{n}=\frac{F_{n+1}}{F_{n}},($ Factorizations of the Fibonacci Infinite Word, Gabriele Fici, 2015)

$G_{n}=\frac{F_{n}+F_{n-1}}{F_{n-1}+F_{n-2}} \quad$ Persamaan

Bentuk persamaan (3) ini dinamakan fungsi barisan Fibonacci untuk nilai perbandingan emas.

Algoritma persamaan (3) dapat ditulis dalam matlab sebagai berikut:

$\mathrm{f}(1)=1, \quad \mathrm{f}(2)=1 \quad$ (nilai Fibonacci)

$\mathrm{g}(1)=1 \quad$ (nilai awal golden ratio)

$\mathrm{n}=0 \quad$ (nilai awal iterasi)

er $=1 \quad$ (nilai awal error awal) 
while er $>1$ e-16 (iterasi berjalan jika error di atas $10^{-16}$ )

$\mathrm{n}=\mathrm{n}+1$

$f(n+2)=f(n+1)+f(n)$

$\mathrm{g}(\mathrm{n}+2)=\mathrm{f}(\mathrm{n}+1) / \mathrm{f}(\mathrm{n})$

$\mathrm{e}(\mathrm{n}+2)=\operatorname{abs}(((\mathrm{g}(\mathrm{n}+2)-\mathrm{g}(\mathrm{n}+1)) / \mathrm{g}(\mathrm{n}+2)))$

$\mathrm{er}=\mathrm{e}(\mathrm{n}+2)$

end

\section{Fungsi Persamaan Kuadrat}

Metode lain untuk mendapatkan nilai perbandingan emas $\varphi$ adalah dengan fungsi eksplisit persamaan kuadrat dari sebuah segment garis lurus dengan posisi titik bagian emas. Metode ini dapat dijelaskan sebagai berikut:

Diberikan suatu segmen garis lurus AC. Titik B berada di antara AC. Posisi titik B adalah merupakan posisi emas di mana segmen garis $A C$ dibagai menjadi dua bagian $p$ dan $q, p=A B$ dan $\mathrm{q}=\mathrm{BC}$. Rasio $\mathrm{p}$ dan $\mathrm{q}$ ekivalen dengan rasio $(\mathrm{p}+\mathrm{q})$ dan $\mathrm{p}$, di mana $\mathrm{p}>\mathrm{q} .($ Md. Akhtaruzzaman and Amir A. Shafie, 2011)

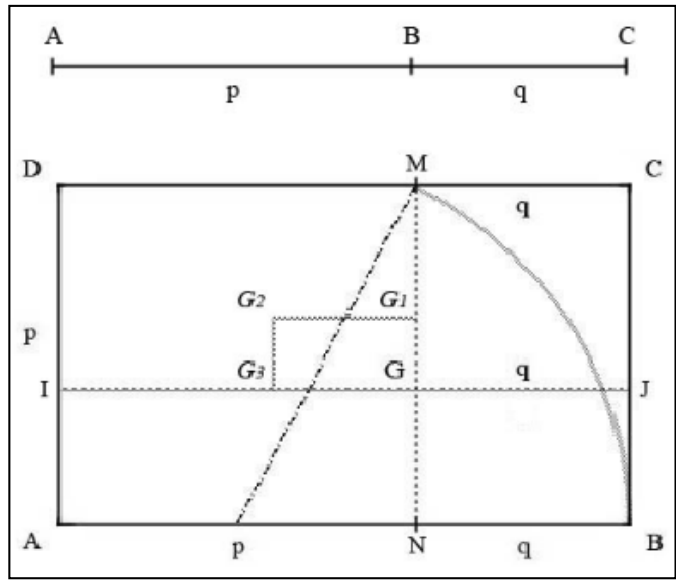

Sumber:article.sapub.org/pdf/10.5923.j.arts.20110101.01.pdf

Gambar 1. Segmen Garis AC dan titik B merupakan posisi emas

Berdasarkan uraian tersebut, maka dapat dituliskan suatu persamaan:

$\varphi=\frac{p}{q}=\frac{p+q}{p}$

Pada sisi kiri :

$\varphi=\frac{p}{q}$

maka

$\frac{q}{p}=\frac{1}{\varphi}$

Persamaan

Pada sisi kanan:

$\varphi=\frac{p+q}{p}$

$\varphi=\frac{p}{p}+\frac{q}{p}$ 
$\varphi=1+\frac{q}{p}$

Persamaan

(5)

Substitusikan persamaan (4) ke persamaan (5), sehingga:

$\varphi=1+\frac{1}{\varphi}$

Kedua ruas masing-masing dikalikan $\varphi$

$\varphi^{2}=\varphi+1$

$\varphi^{2}-\varphi-1=0$

Persamaan

Bentuk persamaan (6) ini merupakan bentuk persamaan kuadrat.

Penyelesaian dari persamaan kuadrat di atas adalah melalui metode numeric posisi palsu (regula false). Metode posisi palsu, bahasa Latin, regula-falsi, merupakan bagian dari metode tertutup atau metode pengurung (bracketing method). Metode ini digunakan untuk menentukan akar-akar dari suatu persamaan kuadrat $f(x)$ yang kontinu dalam selang [a, b]. Dalam selang [a, b] sudah dipastikan berisi minimal satu buah akar. Lelarannya atau iterasinya selalu konvergen atau menuju ke akar persamaan kuadrat dalam selang. Metode tertutup dinamakan juga metode konvergen.

Dalam metode regula-falsi, titik $\mathrm{A}(\mathrm{a}, f(a))$ dan titik $\mathrm{B}(\mathrm{b}, f(b))$ berada pada kurva $f(x)$ . Terdapat titik $\mathrm{C}$ yaitu titik perpotongan antara garis $\mathrm{AB}$ dengan sumbu $\mathrm{x}$. Garis lurus $\mathrm{AB}$ seolaholah berlaku menggantikan kurva $f(x)$ dan memberikan posisi palsu dari akar. Titik C merupakan taksiran akar yang diperbaiki. (J.B. Phillips, AS.Menawafl, S.R. Carden, 2013)

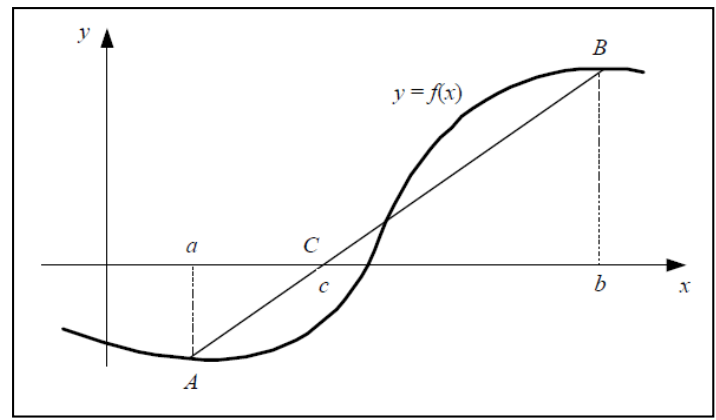

Gambar 2. Metode Posisi Palsu (Regula-Falsi)

Diasumsikan bahwa fungsi $f(\mathrm{x})$ kontinu pada interval (a, $f(\mathrm{a}))$ dan (b, $f(\mathrm{~b}))$ dan $f(\mathrm{a}) \mathrm{x} f(\mathrm{~b})<0$ (perkalian fungsi a dan fungsi $b$ adalah negatif). Berdasarkan asumsi tersebut maka:

Gradien garis $\mathrm{AB}=$ gradien gari $\mathrm{CB}$

$$
\frac{f(b)-f(a)}{b-a}=\frac{f(b)-f(c)}{b-c} \text { Persamaan (7) }
$$

Kurva memotong sumbu $\mathrm{x}$ di titik c,

maka $f(c)=0$

Persamaan (7) menjadi:

$$
\begin{aligned}
& \frac{f(b)-f(a)}{b-a}=\frac{f(b)-0}{b-c} \\
& b-c=\frac{f(b) .(b-a)}{f(b)-f(a)}
\end{aligned}
$$


$c=b-\frac{f(b) \cdot(b-a)}{f(b)-f(a)}$

Berdasarkan ide metode posisi palsu:

$a_{n+1}=c_{n}$

$b_{n+1}=b_{n}$

Persamaan ditulis menjadi:

$c_{n+1}=b_{n}-\frac{f\left(b_{n}\right) \cdot\left(b_{n}-a_{n}\right)}{f\left(b_{n}\right)-f\left(a_{n}\right)} \quad$ Persamaan (8)

Algoritma persamaan (8) dapat ditulis dalam matlab sebagai berikut:

$\mathrm{a}=1$

$\mathrm{b}=-1$ (koefisien $\mathrm{x}^{2}$ )

$\mathrm{c}=-1$

$\mathrm{p}=1$

$\mathrm{q}=2$

er $=1$

(koefisen $\mathrm{x}$ )

(konstanta c)

(batas bawah)

(batas atas)

$\mathrm{n}=0$

(nilai error)

(putaran iterasi)

while er $>1$ e-16 (iterasi berjalan e> 10 $0^{-16}$ )

$\mathrm{n}=\mathrm{n}+1$,

$\mathrm{fp}=\left(\mathrm{a}^{*}\left(\mathrm{p}^{\wedge} 2\right)\right)+\left(\mathrm{b}^{*} \mathrm{p}\right)+\mathrm{c} \quad$ (nilai fungsi $\mathrm{p}$ )

$\mathrm{fq}=\left(\mathrm{a}^{*}\left(\mathrm{q}^{\wedge} 2\right)\right)+\left(\mathrm{b}^{*} \mathrm{q}\right)+\mathrm{c} \quad$ (nilai fungsi $\mathrm{q}$ )

$\mathrm{g}(\mathrm{n})=\mathrm{q}-((\mathrm{fq} *(\mathrm{q}-\mathrm{p}) /(\mathrm{fq}-\mathrm{fp}))) \quad$ (golden ratio)

$\mathrm{p}=\mathrm{g}(\mathrm{n}) ; \quad \quad$ (update nilai batas $\mathrm{p}$ )

$\mathrm{e}(\mathrm{n})=\operatorname{abs}((\mathrm{g}(\mathrm{n})-\mathrm{p}) / \mathrm{g}(\mathrm{n})) \quad$ (nilai error)

er=e(n); (update nilai error)

$\mathrm{p}=\mathrm{g}(\mathrm{n}) ; \quad$ (update nilai batas $\mathrm{p}$ )

\section{HASIL DAN PEMBAHASAN}

Penelitian dilakukan dengan simulasi melalui program pada Matlab versi 7.1 dengan hasil yang simulasi sebagai berikut:

\section{Hasil Simulasi Metode Fungsi Barisan Fibonacci}

Simulasi metode fungsi barisan fibonacci mengasilkan nilai perbandingan emas (golden ratio) atau nilai $\varphi$ sebesar 1.61803398874989 pada iterasi ke-39 dan waktu running sebesar 0.00067885722906. Grafik hasil waktu running fungsi rekursif barisan Fibonacci terdapat dalam Gambar 3. 


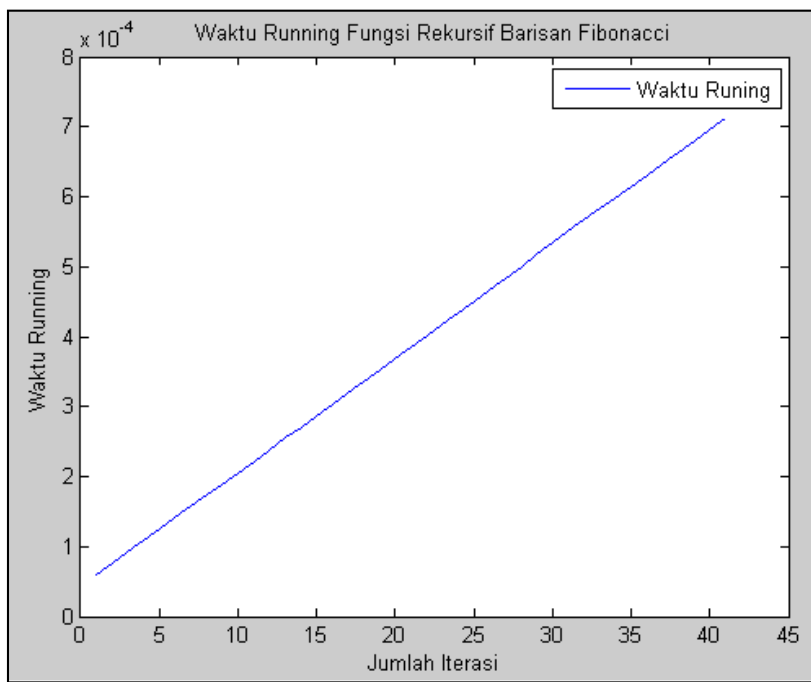

Gambar 3. Grafik Waktu Running pada Fungsi Barisan Fibonacci

Grafik hasil nilai perbandingan emas fungsi barisan Fibonacci tiap iterasi dalam Gambar 4.

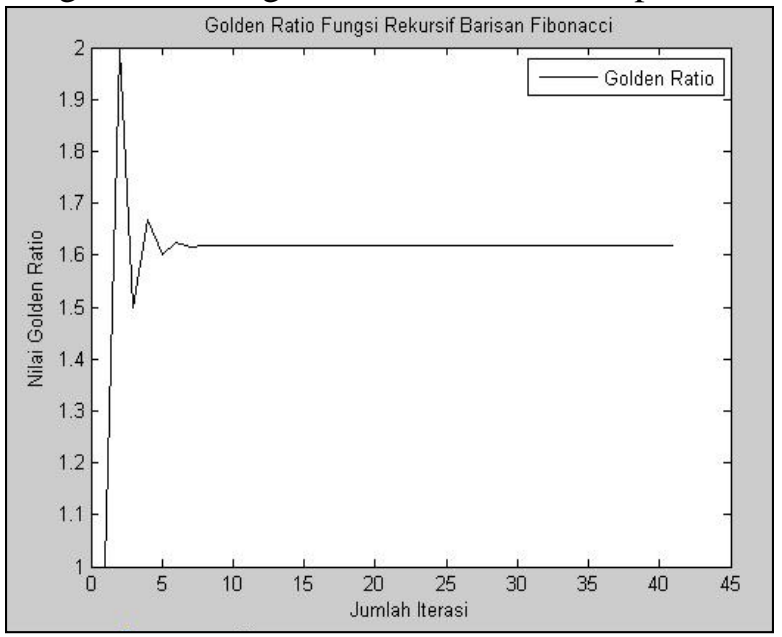

Gambar 4. Grafik Pencapaian Nilai Perbandingan Emas Fungsi Barisan Fibonacci

\section{Hasil Simulasi Metode Numerik Posisi Palsu Fungsi Kuadrat}

Pada metode numerik posisi palsu (regula-falsi) fungsi kuadrat simulasi mengasilkan nilai perbandingan emas (golden ratio) atau nilai $\varphi$ sebesar 1.61803398874989 pada iterasi ke-19 dan waktu running sebesar 0.00046849529759.

Grafik waktu running fungsi persamaan kuadrat terdapat dalam Gambar 5 


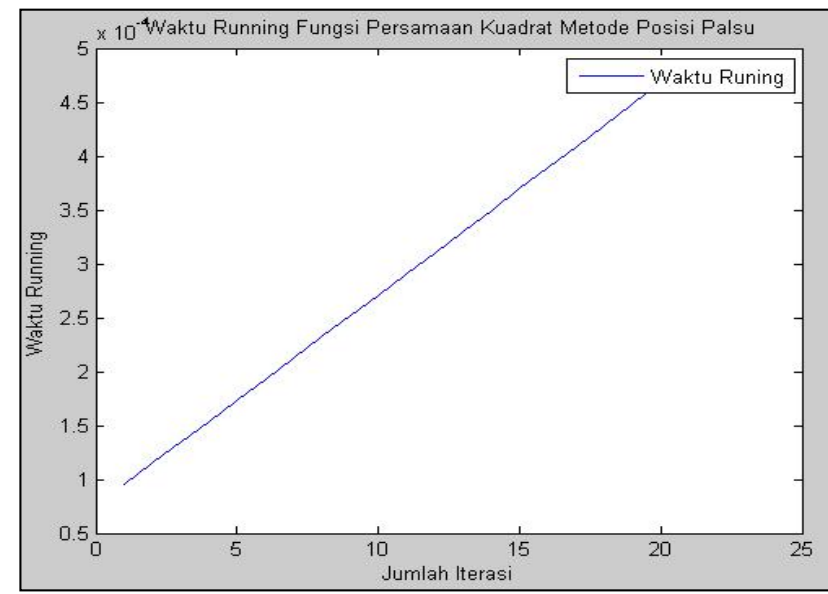

Gambar 5. Grafik Waktu Running pada Fungsi Persamaan Kuadrat

Pencapaian nilai perbandingan emas fungsi persamaan kuadrat terdapat pada gambar 6 .

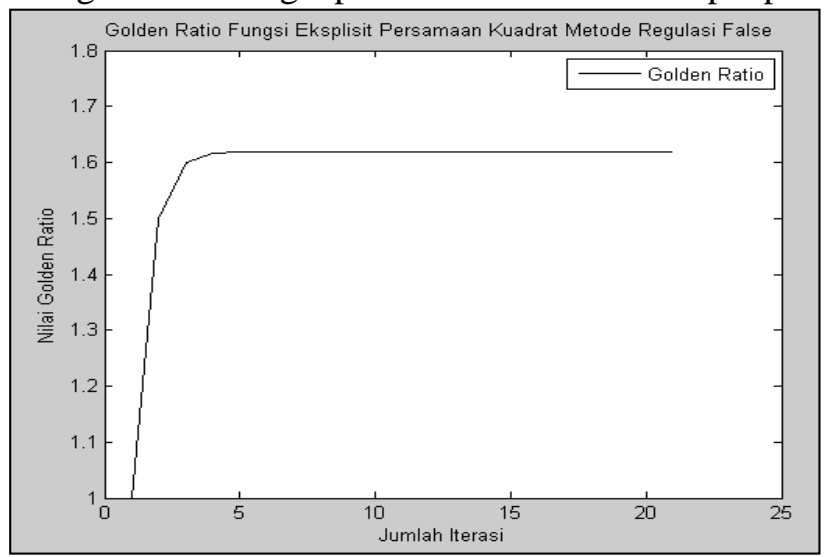

Gambar 6. Grafik Pencapaian Nilai Perbandingan Emas Fungsi Persamaan Kuadrat

Perbandingan Hasil Simulasi antara Metode Fungsi Rekursif Barisan Fibonacci dan Metode Numerik Posisi Palsu Fungsi Kuadrat

Hasil pencapaian nilai perbandingan emas $\varphi$ antara metode persamaan rekursif barisan Fibonacci dengan metode numerik posisi palsu (regula-falsi) persamaan kuadrat mempunyai bentuk yang berbeda. Data pencapaian nilai perbandingan emas masing-masing metode pada tiap iterasi dapat diihat pada tabel 1 .

Tabel 1. Nilai Perbandingan emas Metode Barisan Fibonacci dan MetodeRegula Falsi Persamaan Kuadrat tiap Iterasi

\begin{tabular}{ccc}
\hline No. & Pers. Fibonacci & Per. Kuadrat \\
\hline 1 & 1,00000000000000 & 1,00000000000000 \\
2 & 2,00000000000000 & 1,50000000000000 \\
3 & 1,50000000000000 & 1,60000000000000 \\
4 & 1,66666666666667 & 1,61538461538462 \\
5 & 1,60000000000000 & 1,61764705882353 \\
6 & 1,62500000000000 & 1,61797752808989 \\
7 & 1,61538461538462 & 1,61802575107296 \\
8 & 1,61904761904762 & 1,61803278688525 \\
9 & 1,61764705882353 & 1,61803381340013 \\
\hline
\end{tabular}


Endaryono -Perbandingan Kinerja Metode Barisan .....

\begin{tabular}{rrr}
\hline 10 & 1,61818181818182 & 1,61803396316671 \\
11 & 1,61797752808989 & 1,61803398501736 \\
12 & 1,61805555555556 & 1,61803398820533 \\
13 & 1,61802575107296 & 1,61803398867044 \\
14 & 1,61803713527851 & 1,61803398873830 \\
15 & 1,61803278688525 & 1,61803398874820 \\
16 & 1,61803444782168 & 1,61803398874965 \\
17 & 1,61803381340013 & 1,61803398874986 \\
18 & 1,61803405572755 & 1,61803398874989 \\
19 & 1,61803396316671 & 1,61803398874989 \\
20 & 1,61803399852180 & \\
21 & 1,61803398501736 & \\
22 & 1,61803399017560 & \\
23 & 1,61803398820533 & \\
24 & 1,61803398895790 & \\
25 & 1,61803398867044 & \\
26 & 1,61803398878024 & \\
27 & 1,61803398873830 & \\
28 & 1,61803398875432 & \\
29 & 1,61803398874820 & \\
30 & 1,61803398875054 & \\
31 & 1,61803398874965 & \\
32 & 1,61803398874999 & \\
33 & 1,61803398874986 & \\
34 & 1,61803398874991 & \\
35 & 1,61803398874989 & \\
36 & 1,61803398874990 & \\
37 & 1,61803398874989 & \\
38 & 1,61803398874990 & \\
39 & 1,61803398874989 & \\
Gambar grafik pencapaian nilai perbandingan emas masing-masing metode pada tiap iterasi dapat
\end{tabular}
diihat pada gambar 7 .

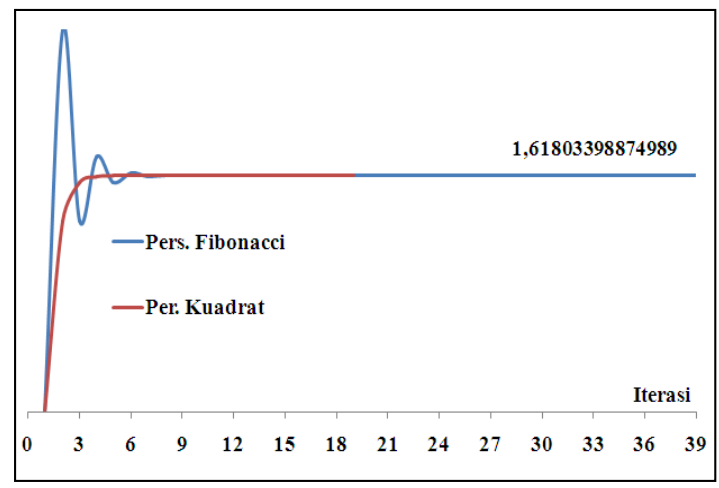

Gambar 7. Grafik Pencapaian Nilai Perbandingan Emas Metode Persamaan Barisan Fibonacci dan Metode Regula-Falsi) persamaan kuadrat tiap Iterasi

Dari tabel 1 dan gambar 10 dapat dipahami bahwa nilai perbandingan emas sebesar 1,61803398874989 pada metode persamaan rekursif barisan Fibonacci didapatkan pada iterasi ke39 dan pada metode numerik posisi palsu persamaan kuadrat dicapai pada iterasi ke-19. 
Kemudian, pencapaian perbandingan emas dari kedua metode ditinjau dari lamanya waktu running, data tersebut dapat diihat pada tabel 2.

Tabel 2. Nilai Waktu Running Metode Barisan Fibonacci dan Metode Regula Falsi Persamaan Kuadrat tiap Iterasi

\begin{tabular}{ccc}
\hline No. & Pers. Fibonacci & Per. Kuadrat \\
\hline 1 & 0,00005922540435 & 0,00009498413905 \\
2 & 0,00007654604147 & 0,00011509842731 \\
3 & 0,00009246985301 & 0,00013465398535 \\
4 & 0,00010839366456 & 0,00015393017828 \\
5 & 0,00012487620633 & 0,00017348573632 \\
6 & 0,00014052065276 & 0,00019304129435 \\
7 & 0,00015700319454 & 0,00021259685239 \\
8 & 0,00017320637120 & 0,00023215241043 \\
9 & 0,00018913018275 & 0,00025170796847 \\
10 & 0,00020533335941 & 0,00027098416139 \\
11 & 0,00022209526630 & 0,00029053971943 \\
12 & 0,00023857780807 & 0,00031037464259 \\
13 & 0,00025533971496 & 0,00033020956574 \\
14 & 0,00027098416139 & 0,00034976512378 \\
15 & 0,00028718733806 & 0,00036987941205 \\
16 & 0,00030339051472 & 0,00038943497009 \\
17 & 0,00031987305649 & 0,00040899052813 \\
18 & 0,00033607623315 & 0,00042826672105 \\
19 & 0,00035255877493 & 0,00044866037443 \\
20 & 0,00036876195159 & 0,00046849529759 \\
21 & 0,00038552385848 & \\
22 & 0,00040144767003 & \\
23 & 0,00041793021180 & \\
24 & 0,00043413338846 & \\
25 & 0,00045061593024 & \\
26 & 0,00046681910690 & \\
27 & 0,00048358101379 & \\
28 & 0,00049978419045 & \\
29 & 0,00051710482757 & \\
30 & 0,00053358736934 & \\
31 & 0,00054979054601 & \\
32 & 0,00056655245290 & \\
33 & 0,00058275562956 & \\
34 & 0,00059840007599 & \\
35 & 0,00061460325265 & \\
36 & 0,00063080642931 & \\
37 & 0,00064700960597 & \\
38 & 0,00066265405240 & \\
39 & 0,00067885722906 & \\
& & \\
& \\
&
\end{tabular}

Grafik nilai waktu running metode persamaan rekursif barisan Fibonacci dan metode numerik posisi palsu (regula-falsi) persamaan kuadrat dalam penentuan perbandingan emas pada tiap iterasi dapat diihat pada gambar 8 . 


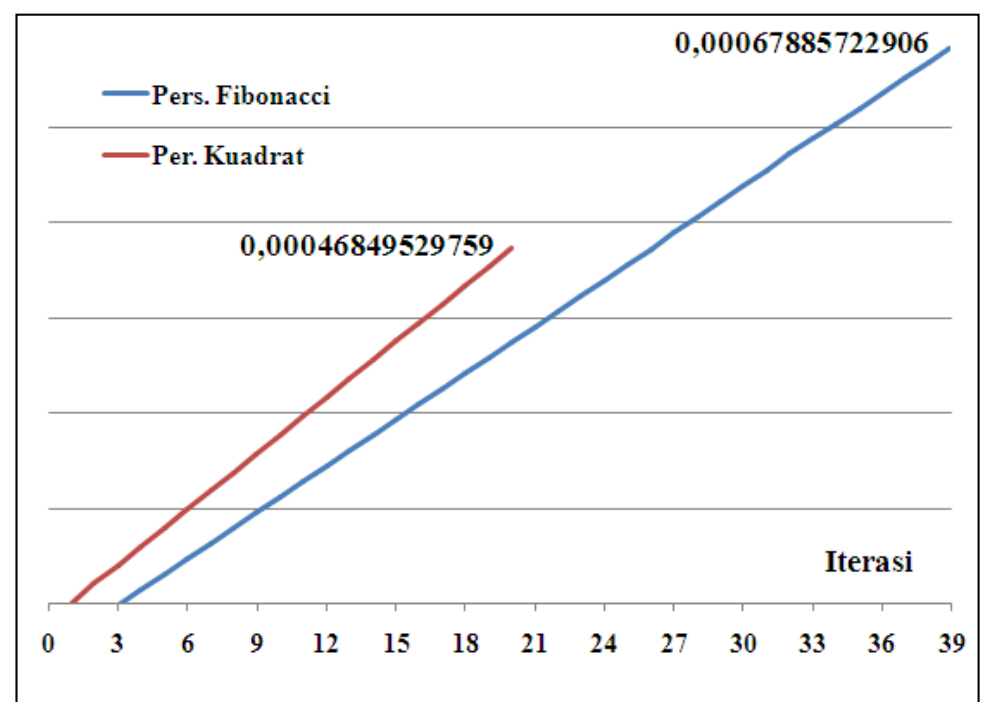

Gambar 8. Grafik Nilai Waktu Running Metode Barisan Fibonacci dan Metode Regula Falsi Persamaan Kuadrat dalam Penentuan Perbandingan Emas

Dari tabel 2 dan gambar 8 dapat dipahami bahwa waktu running yang dibutuhkan untuk mencapai nilai perbandingan emas $\varphi$ pada metode persamaan rekursif barisan Fibonacci adalah 0,00067885722906 dan metode numerik posisi palsu persamaan kuadrat adalah 0,00046849529759 .

\section{PENUTUP}

\section{Simpulan}

Simulasi menghasilkan pada nilai error $1 \times 10^{-16}$ didapat nilai perbandingan emas $(\varphi)$ sebesar 1,61803398874989 pada metode persamaan rekursif barisan Fibonacci terjadi pada iterasi ke-39 dengan waktu running 0.00067885722906 . Pada metode numerik regula falsi fungsi persamaan kuadrat terjadi pada iterasi ke-21 dengan waktu running 0.00049671117419 .

Hasil ini menunjukkan bahwa penggunaan metode numerik regula falsi fungsi persamaan kuadrat memberikan kinerja yang lebih baik dibanding dengan penggunaan fungsi rekursif barisan Fibonacci dalam penentuan nilai perbandingan emas.

Hasil penelitian ini tidak bisa dibandingkan dengan penelitian yang dilakukan Danang Tri Massandy (2012) menyatakan metode HousHolds cocok digunakan untuk mendapatkan nilai perbandingan emas. Penelitian Danang Tri massandy membandingkan kinerja enam metode yang seluruhnya merupakan fungsi eksplisit. Penelitian dalam tulisan ini membandingkan antara fungsi rekursif barisan Fibonacci dan fungsi eksplisit persamaan kuadrat dengan metode numerik regula falsi.

\section{Saran}

Simulasi menghasilkan nilai error, waktu running dan perbandingan emas pada 14 digit setelah koma. Dimungkinkan dilakukan penelitian lanjutan dengan menggunakan jenis komputer yang lebih baik dalam kecepatan proses dan kapasitas memori sehingga menghasilkan penghitungan yang lebih cepat dan teliti dengan meotde lain.

\section{DAFTAR PUSTAKA}

Omotehinwa T.O and Ramon S.O, 2013, Fibonacci Numbers and Golden Ratio in Mathematics and Science". International Journal of Computer and Information Technology (ISSN: $2279-$ 0764), Volume 02- Issue 04, July 2013. 
Tersedia: https://www.ijcit.com/archives/volume2/issue4/Paper020414.pdf

Gabriele Fici. 2015. Factorizations of the Fibonacci Infinite Word“. Journal of Integer Sequences, Vol. 18 (2015), Article 15.9.3.

Tersedia: https://cs.uwaterloo.ca/journals/JIS/VOL18/Fici/fici5.pdf

Md. Akhtaruzzaman and Amir A. Shafie. 2011. Geometrical Substantiation of Phi, the Golden Ratio and the Baroque of Nature, Architecture Design and Engineering". International Journal of Arts. 2011; 1(1):1-22. DOI: 10.5923/j.arts.20110101.01.

Tersedia: http://article.sapub.org/pdf/10.5923.j.arts.20110101.01.pdf

J.B. Phillips, AS.Menawafl, S.R. Carden. 2013. Modification of the Regula Falsi Method to Accelerate System Convergence in the prediction of trace quantities of atmospheric pollutants". Jounal of Hazardous Materals. 44 (1195) 25-35.

Tersedia: https://eurekamag.com/pdf/009/009033731.pdf

Danang Tri Massandy. Perhitungan Nilai Golden Ratio dengan Beberapa Algoritma Solusi Persamaan Nirlanjar, Makalah IF4058 Topik Khusus Informatika I-Sem.II Tahun 2011/2012 Tersedia:http://informatika.stei.itb.ac.id/ rinaldi.munir/MetNum/20112012/Makalah2012/MakalahIF4058-2012-003.pdf

http://www-history.mcs.st-andrews.ac.uk/HistTopics/Golden_ratio.html, uraian pada baris ke-16 